\title{
O Paraíso é para Todos? Diagnóstico sobre Acessibilidade para Pessoas com Deficiência em Unidades de Conservação Federais
}

\author{
Ricardo Gonzales Rocha Souza ${ }^{1,2,3}$ \& Katia Torres Ribeiro ${ }^{1,4}$
}

Recebido em 11/03/2021 - Aceito em 15/11/2021

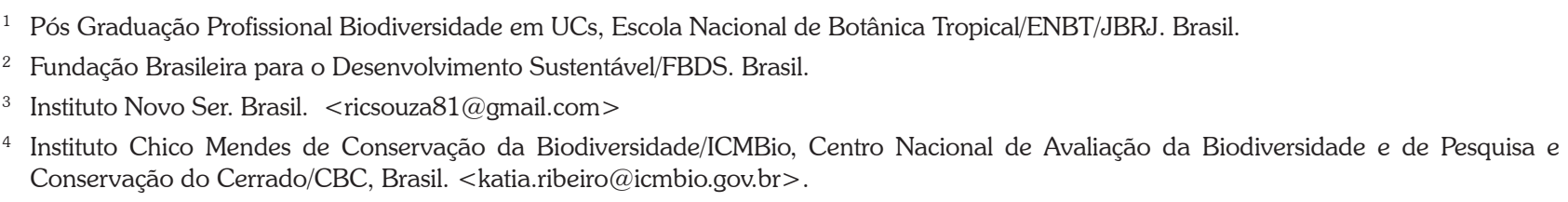

RESUMO - As unidades de conservação (UC), além da conservação da biodiversidade e dos serviços ecossistêmicos, proporcionam significativa conexão das pessoas com a natureza, com inúmeros benefícios de caráter social, cultural, espiritual e para a saúde física e mental. O uso público nas UCs promove ampla gama de desafios, que se agudizam no caso da acessibilidade e inclusão das pessoas com alguma deficiência, que correspondem a quase 1/4 da população brasileira, ou 6,7\% com deficiência mais severa. Trazemos um diagnóstico sobre acessibilidade em parques e florestas nacionais do Brasil, categorias cujos objetivos de gestão ressaltam o uso público e que contam, na esfera federal, com dados recentes sobre condições para o turismo. Foram obtidas 70 respostas aos questionários enviados a equipes de $140 \mathrm{UCs}$, e foram entrevistados 19 usuários com demandas de acessibilidade. Os resultados foram comparados com os dados de condições para a visitação perante o rol de oportunidades de uso público. A existência de iniciativas tem relação direta com o número total de visitantes, bem como com o grau de implementação do uso público. Alguma iniciativa de acessibilidade foi reportada por $36 \%$ das UCs com respostas, sendo muitas vezes derivadas de demanda local, nem sempre previstas em plano de manejo ou uso público. Foram informadas experiências bem-sucedidas que mostram ampla gama de possibilidades e alternativas práticas e viáveis para viabilizar a acessibilidade, e mesmo com as dificuldades atuais, os usuários valorizaram as visitas realizadas. Com ações avulsas e relacionadas a atitudes mais pessoais, ficou clara a premência de institucionalização do tema nos órgãos gestores das UCs, promovendo diretrizes e fomento específico.

Palavras-chave: Áreas protegidas; barreiras de acessibilidade; inclusão social; planejamento do uso público; saúde integral.

\section{The Paradise for All: Assessment of Accessibility for People with Disabilities in Federal Protected Area}

ABSTRACT - Protected natural areas (PAs), such as parks, in addition to the conservation of biodiversity and ecosystem services, provide a significant connection between people and nature, with numerous benefits on social, cultural, spiritual, physical and mental dimensions of live. Nevertheless, public use in PAs carries a wide range of challenges, which become more acute in the case of accessibility and inclusion of people with disabilities, who account for almost $1 / 4$ of the Brazilian population (6.7\% with severe condition). We present a diagnosis of accessibility in National Parks and Forests in Brazil, categories whose management objectives emphasize public use and which have, at the federal level, recent data on conditions for tourism. 70 responses were obtained to the questionnaires sent to teams from 140 PA, and 19 users with accessibility demands were interviewed. The results were compared with data on conditions for visitation according to an array of opportunities for public use. Initiatives towards accessibility are directly related to the total number of visitors as well as to the degree of implementation of public use. Some accessibility initiative was reported by $36 \%$ of the respondent PAs, often an answer to local demands, not always foreseen in a management plan or equivalent document. Successful experiences were reported, showing a wide range of practical and viable possibilities and alternatives to make accessibility real. Even with the current difficulties, users valued the visits made. Spontaneous actions predominate, most related to individual attitudes; they 
are valuable, but evidence the urgent need of institutionalizing the theme in the management bodies of the PA, with guidelines, training and other strategies.

Keywords: Accessibility; disabled people; national parks; protected areas; public use.

\title{
¿Es el Paraíso para Todos? Evaluación de Accesibilidad para Personas con Discapacidades en Áreas Protegidas Federales
}

\begin{abstract}
RESUMEN - Las áreas protegidas (AP), como los parques, además de la conservación de la biodiversidad y los servicios de los ecosistemas, brindan una conexión significativa entre las personas y la naturaleza, con numerosos beneficios de naturaleza social, cultural, espiritual y de salud física y mental. El uso público en las AP promueve una amplia gama de desafíos, que se agudizan en el caso de la accesibilidad e inclusión de las personas con discapacidad, que representan casi la cuarta parte de la población brasileña. Presentamos un diagnóstico de accesibilidad en Parques Nacionales y Bosques en Brasil, categorías cuyos objetivos de gestión enfatizan el uso público y que tienen, a nivel federal, datos recientes sobre condiciones para el turismo. Se obtuvieron 70 respuestas a los cuestionarios enviados a equipos de 140 AP y se entrevistaron 19 usuarios con demandas de accesibilidad. La existencia de iniciativas está directamente relacionada con el número total de visitantes, así como con el grado de implementación del uso público. El 36\% de las AP con respuestas informó alguna iniciativa de accesibilidad, a menudo derivadas de la demanda local, que no siempre están previstas en un plan de gestión o uso público. Se reportaron experiencias exitosas, mostrando un amplio abanico de posibilidades y alternativas prácticas y viables para garantizar la accesibilidad, $e$ incluso con las dificultades actuales, los usuarios valoraron las visitas realizadas. Predominan las acciones espontáneas, la mayoría relacionadas con las actitudes individuales; son valiosos, pero evidencian la urgente necesidad de institucionalizar el tema en los órganos de gestión del AP, con lineamientos, capacitaciones y otras estrategias.
\end{abstract}

Palabras clave: Accesibilidad; áreas protegidas; parques nacionales; personas con discapacidad; uso público.

Look deep into nature, and then you will understand everything better.

Frase atribuída a Albert Einstein

\section{Introdução}

\section{O contato do homem com a natureza e com as áreas protegidas}

Os parques e áreas protegidas afins, da forma como são mais conhecidas hoje em dia, são vistos como um refúgio na natureza diante do desenfreado processo de urbanização das sociedades contemporâneas. Portanto, além da função primordial de conservar a diversidade biológica e a qualidade dos serviços ecossistêmicos, essas áreas podem proporcionar significativa $e$ autêntica conexão do ser humano com a natureza, com inúmeros benefícios de caráter social, cultural, espiritual e para sua saúde física e mental (Maller et al., 2009; Townsend et al., 2015).
A origem dos parques ou áreas naturais protegidas como espaços intencionalmente instituídos para fins específicos e públicos remonta ao século XIX, em um contexto histórico no qual a preservação ativa do meio natural começava a ser vista, no mundo ocidental, como indispensável à sobrevivência da natureza, das pessoas e das sociedades modernas, perante a forte urbanização $e$ a crescente devastação. De acordo com Diegues (2000), a criação do primeiro parque nacional do mundo, nos Estados Unidos da América, foi consequência de um ambiente intelectual em que floresciam ideias preservacionistas que valorizavam o mundo natural ou selvagem (wilderness) pelo seu valor intrínseco, cuja proteção deveria ser promovida para apreciação e recreação do ser humano. 
Esta foi a motivação para a criação dos primeiros parques - como o Parque de Yellowstone, nos Estados Unidos, em 1872, e o Parque Nacional de Itatiaia, no Brasil, em 1937: a preservação do meio natural diante da crescente pressão antrópica, tanto para a conservação do patrimônio natural quanto para o desfrute das pessoas da cidade (Aguiar et al., 2013; Franco et al., 2015). Essas ideias influenciaram fortemente outros países, que aderiram ao movimento de criação de parques. No percurso histórico, as áreas naturais protegidas tornaram-se instrumento dos mais importantes para a conservação da biodiversidade (Franco et al., 2015), para a promoção do contato do ser humano com o meio selvagem assim como para a garantia de diferentes modos de vida.

No Brasil, entre as áreas protegidas estão as terras indígenas, as terras quilombolas $e$ as unidades de conservação, estas com 12 categorias de manejo, como os parques, incluindo áreas particulares. A palavra parque é adotada neste texto na sua conotação em inglês, denotando conjunto de áreas protegidas que têm o uso público como um de seus objetivos de criação e gestão.

O uso público, em alguma modalidade, é previsto em todas as 12 categorias de manejo e gestão das unidades de conservação (UCs), nas esferas federal, estadual e municipal (Lei n ${ }^{\circ} 9.985$ de 2000, que institui o Sistema Nacional de Unidades de Conservação - SNUC), com o objetivo $\mathrm{d} e$ "favorecer condições e promover a educação $e$ interpretação ambiental, a recreação em contato com a natureza e o turismo ecológico". Em algumas categorias a visitação é restrita à pesquisa $e$ educação ambiental $e$ em outras a recreação é estimulada e corresponde a um dos objetivos a serem alcançados pela gestão, como no caso dos parques e florestas (nacionais, estaduais ou municipais).

\section{Relação de benefício mútuo da visitação para as pessoas e para os parques}

É senso comum que uma caminhada no parque, respirar o ar puro do campo ou ter contato mais próximo com a natureza geram bem-estar e relaxamento imediato. $\mathrm{O}$ benefício desse contato é muito extenso, como mostrou o estudo pioneiro de Ulrich (1984) sobre os efeitos positivos do contato visual com o ambiente natural através de uma janela para a recuperação de pacientes em período pós-operatório. Cresce o número de médicos que prescrevem a exposição a ambientes naturais como tratamento para o estresse e outros acometimentos (Razani et al., 2018; Zarr et al., 2017). Nos Estados Unidos, o Park $R x$ (em português, "prescrição de parques"; $\mathrm{Rx}$ significa prescrição), em parceria com o National Park Service (NPS), oferece informações e suporte para que os profissionais da saúde e os ligados à gestão dos parques incorporem em sua rotina a prescrição da natureza (Park $\mathrm{Rx}$, 2018). No Japão, o Shinrinyoku - em português, "banho de floresta" - que envolve caminhadas contemplativas regulares em trilhas suaves e sem dificuldade para fins de relaxamento e prevenção de doenças, é incentivado pelo governo e pela sociedade médica desde a década de 1980 (Li, 2008; Park, 2010).

O Healthy Parks Healthy People - HPHP (Parques Saudáveis, Pessoas Saudáveis, em português) é um destacado movimento global que reconhece a relação fundamental que existe entre a saúde das pessoas e a do meio ambiente, $e$ tem como principal objetivo despertar a sociedade para o potencial que a natureza $e$ os parques possuem para a prevenção $e$ restauração da saúde e bem-estar humanos (Parks Victoria, 2019). Há evidências de que nos ambientes com maior biodiversidade os benefícios para a saúde e o bem-estar também são maiores (Fuller et al., 2007; Who, 2015).

Outro exemplo é o movimento norteamericano Leave no children inside (levem todas as crianças para fora, em tradução livre), que reconhece o déficit de natureza como catalizador de desordens físicas e psíquicas no desenvolvimento das crianças, com uma conclamação para mudanças e propostas estruturais para promover a retomada deste convívio (Louv, 2007).

Se por um lado as áreas protegidas apresentam estes benefícios para as pessoas $e$ para a sociedade, por outro lado, estudos apontam para a importância da frequência de visitantes e do sentimento de conexão das pessoas com a natureza (nature connectedness) para a construção de uma cultura conservacionista e o fortalecimento dos parques na sociedade. Wright \& Matthews (2015), em revisão da literatura, sustentam que a desconexão crescente das crianças, em especial, assim como dos adultos em relação aos ambientes naturais $e$, ao mesmo tempo, a piora nas condições ecológicas do planeta, tornam prioritária para muitas organizações relacionadas 
ao tema a promoção do envolvimento das pessoas com a natureza, visando também a (re)construção do apoio político aos parques e a questões conservacionistas. A ampliação e diversificação de atividades está em pauta e sabe-se que aquelas que produzem um impacto emocional mais forte - meaningful nature experiences, no inglês, apresentam o maior potencial de intensificar esse sentimento de conexão (Tilden, 1977) e, em consequência, podem gerar novas atitudes positivas perante a natureza.

\section{Barreiras de acesso à visitação nas unidades de conservação}

São muitas as barreiras de acesso às áreas naturais protegidas, a começar pelo pequeno número de UC que estão aptas a receber visitantes de modo qualificado. Das 334 UCs federais existentes, apenas $36 \%$ relataram visitação em 2018 , e no caso dos parques nacionais, categoria em que há maior visitação, somente 69\% (51 de 74 unidades) estavam então abertos oficialmente à visitação (ICMBio 2019a, b). As dificuldades se intensificam no caso de pessoas com deficiência.

Com cerca de $23,9 \%$ da população com algum grau de deficiência, $6,7 \%$ com quadros mais severos de dificuldade de realizar atividades cotidianas (IBGE, 2010, 2018), e com o trágico quadro socioeconômico de assimetrias abissais, é evidente que o país tem graves e numerosos déficits no campo da inclusão social e na prestação de serviços minimamente adequados, seja na esfera pública ou privada. No entanto, são muitos também os potenciais de atuação da sociedade e das instituições na garantia de direitos, de promoção da saúde e prevenção de doenças na área da acessibilidade, assim como na promoção de novas oportunidades e nichos de mercado, no que se refere ao lazer e à recreação.

De acordo com a Convenção sobre os Direitos das Pessoas com Deficiência da ONU de 2007, ratificada no Brasil com o Decreto $n^{\circ}$ 6.949/2009, "Pessoas com deficiência são aquelas que têm impedimentos de longo prazo de natureza física, mental, intelectual ou sensorial, os quais, em interação com diversas barreiras, podem obstruir sua participação plena e efetiva na sociedade em igualdades de condições com as demais pessoas". Adota-se a expressão "Pessoa com deficiência" em lugar de outros entendidos como discriminatórios ou pejorativos, pois ao dizer-se "pessoa" antes da palavra deficiência valoriza-se o ser humano que apresenta a deficiência, que passa a ser uma entre tantas outras de suas características.

A deficiência é entendida como resultante da interação entre as características das pessoas com as diferentes barreiras apresentadas pelos ambientes com os quais interagem, que podem ser de natureza arquitetônica, comunicacional, atitudinal, entre outras. Ela emerge do resultado desta interação, mostrando-se de maior ou menor grau em função das características do ambiente e limitando/impedindo ou não a participação efetiva das pessoas na sociedade (Corde, 2008). Um exemplo no contexto deste trabalho é o de uma pessoa surda em visita a um parque para experienciar uma trilha guiada: a presença ou não de pessoal treinado em Língua Brasileira de Sinais - Libras vai impactar a qualidade da experiência $e$ a expressão da deficiência naquele contexto $e$ momento.

As barreiras de acessibilidade podem ser das mais sutis e imperceptíveis às mais visíveis e óbvias; as barreiras arquitetônicas são as mais mencionadas pela mídia e pela sociedade. Sassaki (2003) classifica as barreiras de acessibilidade nos ambientes de lazer, recreação e turismo da seguinte forma: i. barreiras arquitetônicas, em todo o trajeto a ser percorrido, dos aeroportos aos locais de acampamento; ii. barreiras atitudinais, da sociedade como um todo, especialmente entre aqueles com poder de decisão política, mas que não abrem as oportunidades para as pessoas com deficiência; iii. barreiras comunicacionais, nas sinalizações e na não contratação de pessoal especializado; iv. barreiras metodológicas, na forma tradicional, pela falta de oferta de programas inteiramente adequados; v. barreiras instrumentais, nos vários dispositivos nos locais de visitação que ignoram possíveis limitações físicas, sensoriais e mentais dos visitantes; $e$ vi. barreiras programáticas, constantes nos planos e normativas, que são não-explícitas, mas pervasivas e impactantes. Para que exista um ambiente de fato inclusivo, ou livre de barreiras, $e$ qualquer pessoa, com ou sem deficiência, possa ter plena participação e exercer seu direito de ir e vir, as seis categorias de acessibilidade devem ser observadas.

O presente trabalho traz uma avaliação do grau de planejamento e implementação da acessibilidade para pessoas com deficiência em UCs federais do Brasil, considerando as 
florestas e parques nacionais, visando contribuir para a reflexão sobre possíveis caminhos para o aprimoramento da acessibilidade nessas UCs. Apoia essa discussão a análise do corpo normativo brasileiro sobre acessibilidade existentes para parques e/ou áreas afins na esfera federal $e$ a análise de experiências positivas em outros países.

\section{Materiais e Métodos}

Este estudo tem como base metodológica a pesquisa do tipo exploratória, que de acordo com Gil (2008), é a mais indicada para assuntos ainda pouco aprofundados. Para o levantamento $e$ a caracterização de iniciativas de acessibilidade já implementadas em UC, delimitou-se a abrangência da pesquisa à esfera federal, abarcando os parques e florestas nacionais, categorias que têm o uso público como um de seus objetivos de manejo e que juntos representam cerca de $90 \%$ de toda a visitação às UCs federais registrada em 2016 (Souza 2016). A escolha deve-se também à disponibilidade de informações já consolidadas por Souza (2016) sobre a estrutura geral de apoio ao uso público para este conjunto de UC.

O levantamento foi dividido em três abordagens. Primeiramente, por meio da observação participante (o primeiro autor é cadeirante, tetraplégico, devido a um acidente automobilístico) em três parques nacionais com iniciativas de acessibilidade implementadas: da Tijuca, da Chapada dos Veadeiros e da Serra dos Órgãos, quando foram feitos contatos presenciais com as equipes gestoras, assim como registros $e$ observações locais.

A segunda abordagem foi o levantamento sistemático de informações sobre a existência $e$ as características das iniciativas de uso público e de acessibilidade junto aos gestores das 140 UCs das categorias parque nacional (PARNA) $e$ floresta nacional (FLONA), mediante aplicação de questionário estruturado online (Souza, 2019). O questionário foi enviado para uma lista de e-mails obtida junto ao órgão gestor, o Instituto Chico Mendes de Conservação da Biodiversidade (ICMBio), após a aprovação da pesquisa via Sistema de Informação e Autorização em Biodiversidade (SISBio). O questionário foi enviado a partir de 27 de setembro de 2018 conforme iam sendo liberadas as autorizações de pesquisa para conjuntos de UCs. Foi feito reforço de pedido de preenchimento ao menos quatro vezes, com intervalo mínimo de uma semana. Os resultados foram tabulados $e$ analisados considerando cada questão separadamente.

Adicionalmente foi feita uma análise comparando UCs com e sem medidas de acessibilidade implementadas em função do número de visitantes e do índice de atratividade turística das unidades para as UCs federais. Tal índice, conforme Souza et al. (2017), baseia-se na metodologia conhecida como Recreation Opportunity Spectrum (ROS) - adaptada para América Latina com o nome de Rango de Oportunidades de Visitação em Áreas Protegidas (ROVAP) e, posteriormente, para o Brasil como Rol de Oportunidades de Visitação em Unidades de Conservação (ROVUC) - para determinar a classe de atratividade turística de cada UC federal do SNUC. A classificação tem como base atributos sociais, físicos e gerenciais, tanto da unidade como do seu entorno, traduzindo-se no maior ou menor grau de atratividade e na capacidade da UC enquanto destinação turística. As classes podem variar de áreas totalmente primitivas, sem infraestrutura e poucos visitantes, a regiões intensamente desenvolvidas, com paisagem natural modificada e oferta de serviços diversificada para receber muitos tipos e quantidade de turistas. São cinco os tipos de classes: primitiva, semiprimitiva, extensiva, intensiva e altamente intensiva. Foi aplicada uma regressão linear simples para avaliar o grau de correlação existente entre a classe de atratividade turística $e$ a visitação das UCs, considerando de forma comparativa as unidades com e sem medidas implementadas. Foram consideradas as 36 unidades participantes desta pesquisa cujas classes de atratividade estavam disponíveis em Souza et al. (2017).

A terceira abordagem foi a pesquisa com visitantes com deficiência ou mobilidade reduzida das UCs identificadas na etapa anterior que dispusessem de alguma iniciativa de acessibilidade implementada e cujas equipes aderissem à proposta. Foi feita a aplicação de questionário semiestruturado presencial durante o período de um mês, por meio do qual se procurou caracterizar a percepção e a expectativa dos visitantes com respeito aos benefícios relacionados às vivências na natureza, visando a conhecer seu grau de satisfação e os benefícios da experiência para sua qualidade de vida bem como para seu conhecimento sobre o ambiente natural ou bioma visitado (vide Souza, 2019). 


\section{Resultados \\ Visitas de campo}

\section{Parque Nacional Tijuca}

Fica localizado no coração da cidade do Rio de Janeiro. Abrange uma área total de 3.953ha de Mata Atlântica coberta por Floresta Ombrófila Densa e abriga muitos atrativos turísticos. Esta visita teve como objetivo fazer o primeiro contato com a cadeira Julietti, que permite o desfrute de trilhas acidentadas (Figura 1; ver também www.montanhaparatodos.com.br), assim como conversar com servidores responsáveis pelas atividades. A visita foi feita pelo acesso no Alto da Boa Vista, não incluindo as áreas com muitas intervenções, como o Corcovado e o Centro de Visitantes. Informou-se que a cadeira está à disposição de visitantes, mas ainda é muito pouco utilizada, e há alguns guias capacitados para a condução da cadeira que podem ser contratados.

O parque possui uma trilha acessivel, o Caminho Dom Pedro Augusto, inaugurada em 2011 em comemoração aos 150 anos da Floresta da Tijuca. Com 630m de extensão, distingue-se de uma trilha convencional por ser plana, larga e sem obstáculos e, além disso, dispõe de placas interpretativas em braile e cabo autoguia ao longo do percurso, tornando-a apropriada para pessoas com deficiência física ou visual (Figura 2).

\section{Parque Nacional da Chapada dos Veadeiros}

Com 240 mil hectares, localiza-se nos municípios de Alto Paraíso de Goiás e Cavalcante, no estado de Goiás, distante cerca de $230 \mathrm{~km}$ de Brasília e 400km de Goiânia. Declarado Patrimônio Natural da Humanidade pela UNESCO em 2001, tem numerosas trilhas, cachoeiras e outros atrativos naturais que recebem milhares de turistas ao longo do ano.

$\mathrm{O}$ parque apresenta as seguintes iniciativas voltadas para pessoas com deficiência: i. Estacionamento: vagas reservadas para pessoas com deficiência e acesso através de rampa para o centro de visitantes; ii. Centro de visitantes: rampas, banheiro acessível para deficientes físicos e ausência de desníveis; iii. Trilha suspensa: passarela de madeira de 230 metros com corrimão, desenvolvida no padrão da norma ABNT 9050 (ABNT, 2015), que termina na beira do Rio Preto e nas Corredeiras, um dos atrativos do parque. Para chegar até a trilha é necessário o uso de um veículo com tração $4 \times 4$, cujo uso é autorizado às pessoas com deficiência; iv. Cadeira Julietti: cadeira de rodas desenvolvida para prática do montanhismo que permite o acesso a diversas trilhas do parque (Figura 1). Existem alguns guias treinados que podem ser contratados para a condução da cadeira.

As adaptações ou medidas de acessibilidade presentes no parque, embora em pequeno número, significam muito em termos de acesso, uma vez que facultam, em particular a visitantes com deficiência física, acesso a atrativos variados em ambientes naturais antes impossíveis de se atingir. No entanto, não há iniciativas direcionadas a pessoas com deficiência visual, auditiva ou intelectual.

\section{Parque Nacional da Serra dos Órgãos}

Com 20 mil hectares na região central do estado do Rio de Janeiro, abriga montanhas, vertentes vertiginosas, cachoeiras e espécies endêmicas da Mata Atlântica, e tornou-se acessível a um número maior de visitantes graças a algumas iniciativas desenvolvidas pela equipe gestora do parque.

Visitou-se a trilha suspensa, que proporciona ao visitante uma experiência muito significativa de imersão na floresta. A passarela, de madeira e com corrimão, tem $1.300 \mathrm{~m}$ de extensão e está situada na altura entre o dossel e o sub-bosque, constituindo uma oportunidade muito rara de contato com espécies da flora e fauna locais e uma visão mais ampla da área, especialmente interessante a pessoas com deficiência física, que geralmente têm seu deslocamento limitado em regióes de mata, e também a pessoas com outras deficiências (visual, auditiva e intelectual) (Figura 2). O parque dispõe também, desde 2017, de uma cadeira Julietti, o que amplia sua oferta de atividades inclusivas. 

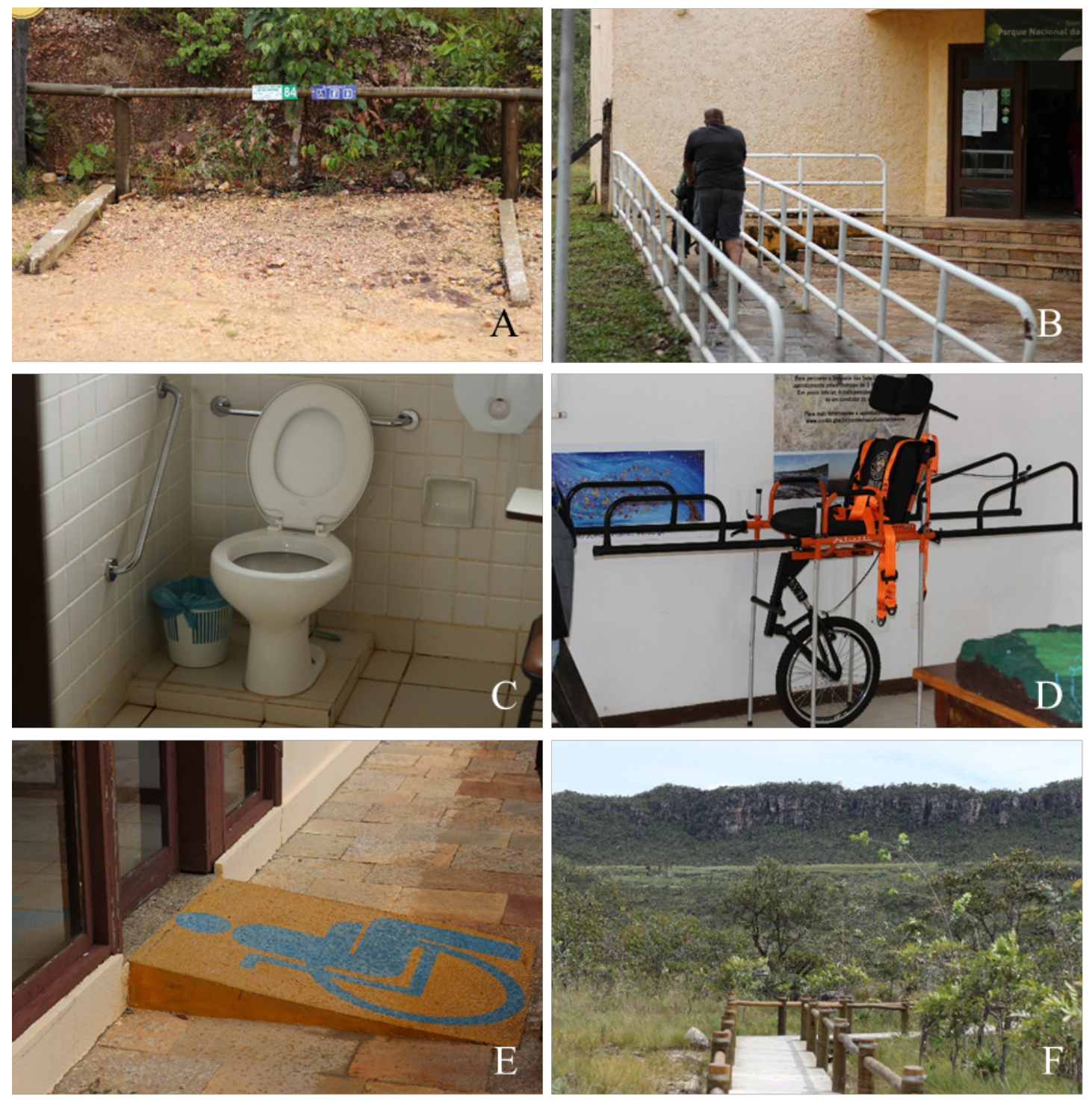

Figura 1 - Parque Nacional da Chapada dos Veadeiros. A) Estacionamento com vagas reservadas para pessoas com deficiência. B) Rampa de acesso ao centro de visitantes. C) Banheiro adaptado com barras de apoio. D) Cadeira Julietti. E) Rampa de acesso à área externa do centro de visitantes. F) Trilha suspensa com 230 metros para acesso ao Rio Preto. 

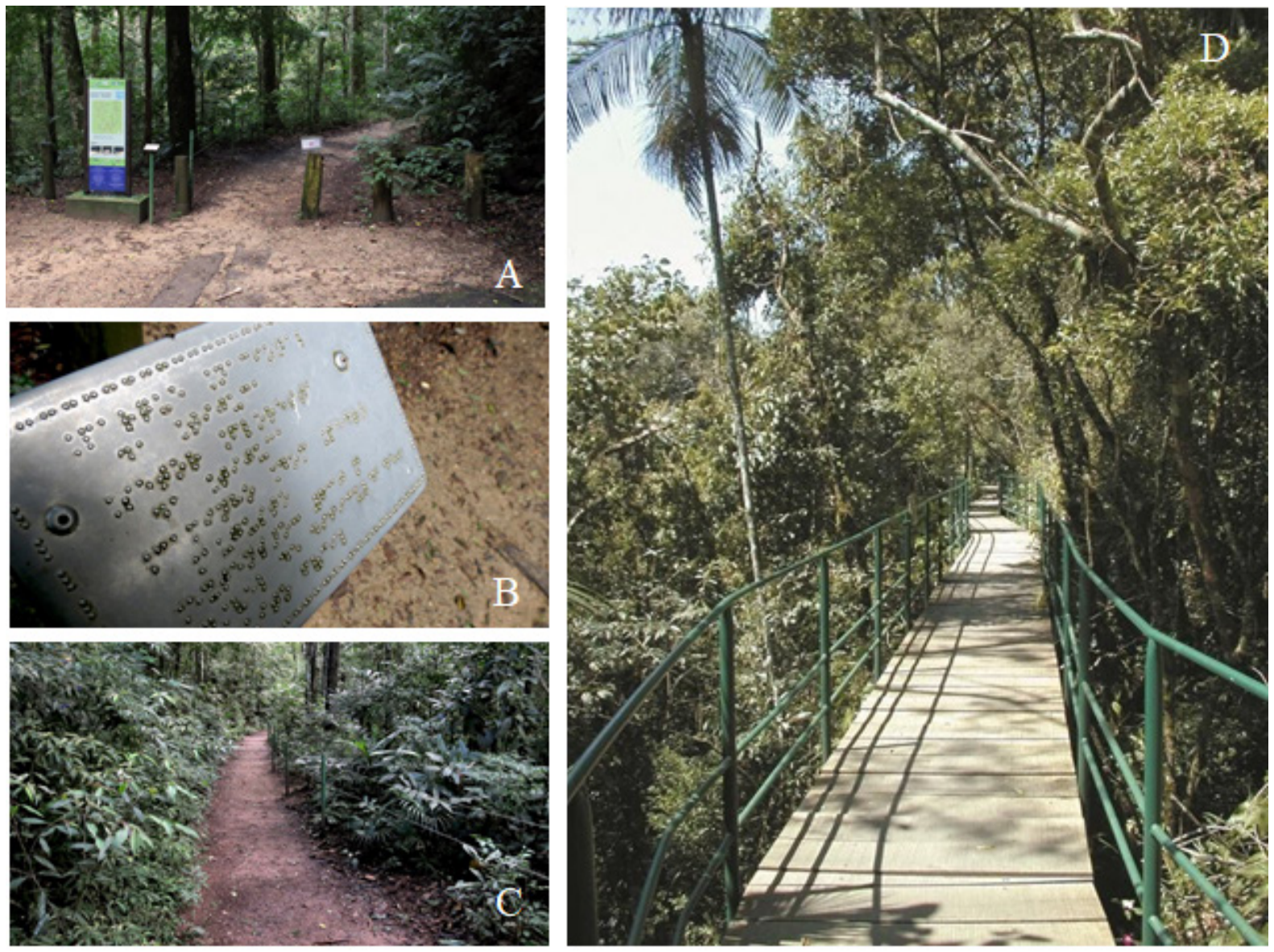

Figura 2 - Parque Nacional da Tijuca. A) Início da trilha acessível. B) Placa de sinalização interpretativa em braile. C) Trecho da trilha demonstrando o terreno plano e de fácil circulação. Fonte: Trilhas (2019); D) Trilha suspensa no Parque Nacional da Serra dos Órgãos. Fonte: PARNASO (2019).

\section{Diagnóstico de acessibilidade das unidades de conservação federais}

\section{Informações e percepções trazidas pelos gestores}

Gestores de 70 das 140 UCs (50\%) abarcadas pelo estudo responderam ao questionário. Este conjunto concentra $92,6 \%$ da visitação registrada em 2018 nos parques e florestas nacionais (8.454.604 de 9.132.597 visitantes registrados ICMBio, 2018). Houve uma boa distribuição da amostra entre as regiões do país, com acréscimo da região "mar" para classificar as unidades oceânicas, não litorâneas, por suas características muito específicas de visitação: Norte - 22\%; Nordeste - 21\%; Sudeste - 23\%; Centro-Oeste - 4\%, Sul - 26\% e Mar - 4\% (porcentagem da amostra de 70 UC, sem ponderar pelo número de UCs em cada região).

\section{Acessibilidade no plano de manejo}

As primeiras questões dirigidas aos gestores foram relacionadas ao plano de manejo da área, tendo em vista se tratar do documento que estabelece as normas e objetivos, inclusive quanto à visitação e ao uso público. As UCs que afirmaram que a questão da acessibilidade está contemplada no plano de manejo, em plano de uso público ou similar representam $33 \%$ das respostas. Daquelas que têm programa de uso público ou similar incluído nesse instrumento de gestão ( $81 \%$ ), $39 \%$ preveem a acessibilidade no documento. As respostas reproduzidas abaixo ajudam a entender, em certa parte, alguns fatores relacionados a esse número baixo e a dinâmica da relação prática entre a implementação da acessibilidade e sua previsão no plano de manejo: 
"À época da elaboração do Plano de Manejo a acessibilidade não estava em voga"; "Ainda não temos plano de manejo mas a questão de acessibilidade será abordada no plano específico de uso público"; "Visualizamos que a cada dia aumenta a necessidade de inclusão social das pessoas com deficiência, por isso a gestão das unidades precisa se adaptar a essas necessidades"; "A Unidade ainda não possui Plano de Manejo até o momento, o que não impede que seja inserido em seu corpo medidas que favorecem a acessibilidade de pessoas com deficiência".

\section{Ocorrência de acessibilidade nas unidades}

A distribuição geográfica das unidades com alguma medida de acessibilidade implementada se dá da seguinte maneira: Sudeste $-32 \%$, Nordeste $-24 \%$, Sul $-24 \%$, Centro-oeste $-8 \%$, Norte $-4 \%$ e Mar $-8 \%$. A Figura 3 agrupa as informações sobre uso público, plano de manejo e ocorrência de acessibilidade em função da distribuição geográfica das UCs participantes da pesquisa.

Cerca de 25 UCs (correspondendo a 36\% das respostas recebidas) indicaram haver alguma medida de acessibilidade implementada na unidade, mas há pouca relação entre a existência de iniciativa de acessibilidade $e$ a sua previsão no plano de manejo. Cerca de metade das UCs respondentes têm iniciativas implementadas $e$ previsão formal de acessibilidade. Das $23 \mathrm{com}$ previsão de acessibilidade em plano de manejo ou de uso público, 13 têm iniciativas implementadas. No entanto, das 47 sem medidas previstas, 12 têm medidas implementadas.

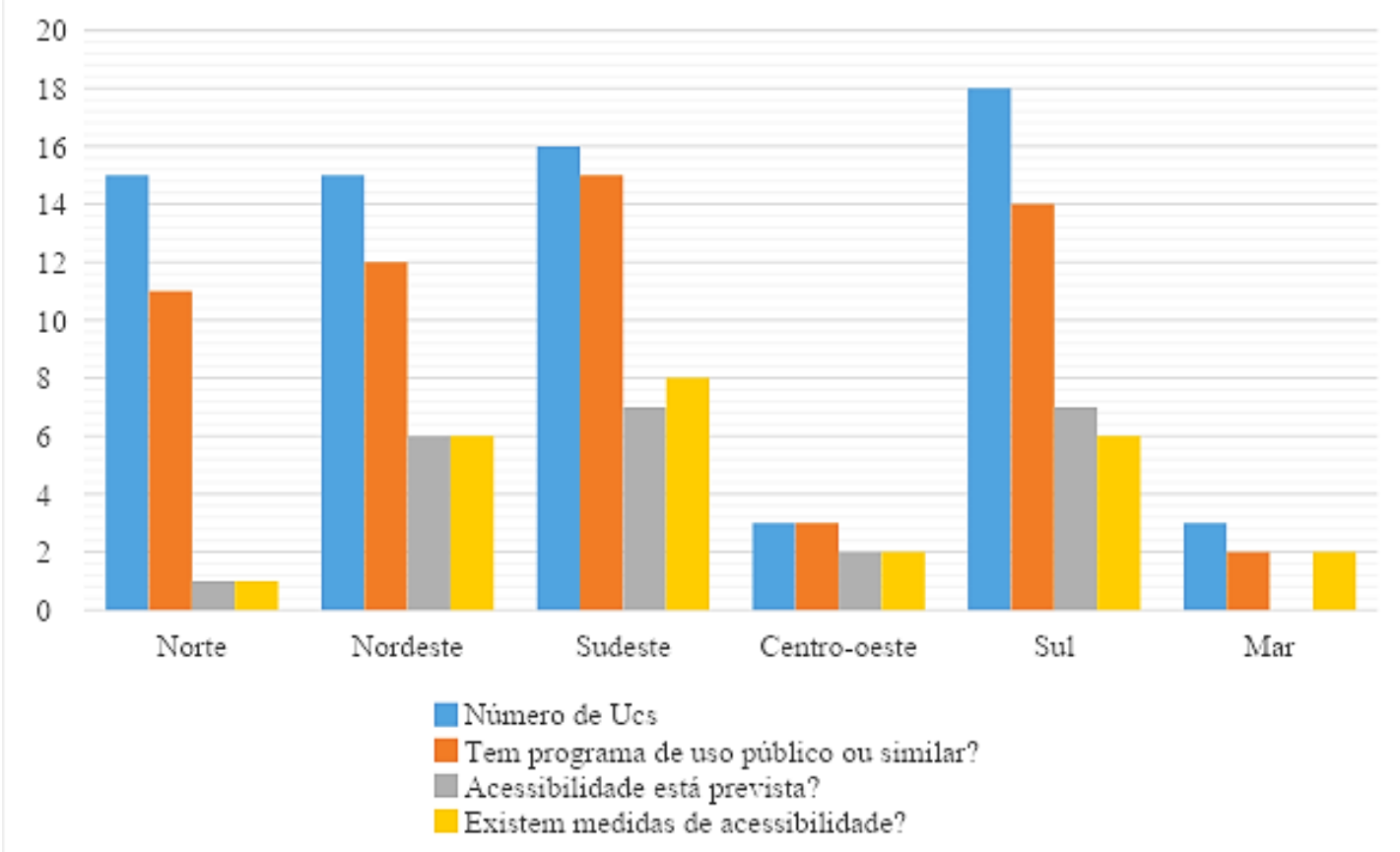

Figura 3 - Quantidade de unidades de conservação que têm programa de uso público, previsão de acessibilidade no plano de manejo e ocorrência de acessibilidade por região.

Comentários destacados:

"Quando recebemos a solicitação via SISBio louvamos a Deus pela pesquisa, pois sonhamos com acessibilidade para Cadeirantes e Visual poderem desfrutar das belezas das Unidades de Conservação "; "As novas estruturas consideram a questão da acessibilidade (rampas, elevadores, piso tátil etc.) e o parque implantou em 2011 uma trilha acessível, com cabo-guia, placas em braile e piso regularizado. A motivação é o acesso fácil ao Parque, que pode ser a única oportunidade de pessoas com dificuldades terem contato com o ambiente natural"; "Existe demanda, mas, temos baixa capacidade operacional"; "Precisamos de apoio institucional para implantar atividades para especiais". 
Tabela 1 - Ocorrência de medidas de acessibilidade nas unidades de conservação.

\begin{tabular}{|c|c|c|}
\hline \multicolumn{3}{|l|}{ Pergunta } \\
\hline Existem medidas que favorecem a acessibilidade de pessoas com deficiência na UC? & Sim $-36 \%$ & Não - $64 \%$ \\
\hline Se sim, o que motivou? * & Qte & $\%$ \\
\hline motivação pessoal do gestor & 16 & $64 \%$ \\
\hline demanda de usuários & 9 & $36 \%$ \\
\hline demanda do conselho gestor & 6 & $24 \%$ \\
\hline projetos e parcerias & 6 & $24 \%$ \\
\hline demanda da comunidade do entorno & 6 & $24 \%$ \\
\hline obrigação legal & 2 & $8 \%$ \\
\hline concessão de uso & 1 & $4 \%$ \\
\hline cobrança do Ministério Público Federal & 1 & $4 \%$ \\
\hline \multicolumn{3}{|l|}{ Se não, assinale a razão* } \\
\hline carência de recursos financeiros & 26 & $58 \%$ \\
\hline inexistência ou pouca demanda & 21 & $47 \%$ \\
\hline falta de conhecimento técnico & 15 & $33 \%$ \\
\hline não constam; ou inexistência de plano de manejo & 8 & $18 \%$ \\
\hline sem capacidade operacional & 2 & $4 \%$ \\
\hline inviabilidade técnica & 2 & $4 \%$ \\
\hline sem estrutura de uso público & 2 & $4 \%$ \\
\hline regularização fundiária ou outros conflitos & 2 & $4 \%$ \\
\hline desconhece o motivo & 1 & $2 \%$ \\
\hline * As respostas não foram excludentes entre si. & & \\
\hline
\end{tabular}

Perguntou-se também sobre futuros projetos de acessibilidade. Cerca de $40 \%$ dos respondentes afirmaram haver projetos a serem executados, principalmente voltados para adequação da acessibilidade arquitetônica, criação de trilhas adaptadas, aquisição de cadeiras Julietti, acesso a mirantes, cachoeiras e outros. A grande maioria (96\%) afirmou que faltam recursos financeiros para a execução dos projetos, enquanto a falta de conhecimento técnico $(37 \%)$ é a segunda principal causa.

\section{Acessibilidade $e$ índice de atratividade turística}

Observamos que as unidades com iniciativas de acessibilidade, em sua maioria, têm visitação maior que as sem medidas implementadas. Temse ainda uma relação positiva entre número de visitantes e índice de atratividade turística, tanto no caso do conjunto de UCs com acessibilidade como naqueles sem iniciativas, no entanto, a relação é mais estreita no primeiro caso $\left(R^{2}=0,54\right.$ vs $\mathrm{R}^{2}=0,10$, vide Figura 4). Pode-se depreender então que as unidades dotadas dos melhores atributos internos e/ou do seu entorno recebem mais visitantes e também estão mais estruturadas em relação à acessibilidade. Estas são, em geral, as UCs localizadas próximas aos grandes centros urbanos. Vê-se que todas as UCs com maior índice de atratividade declararam dispor de iniciativas de acessibilidade, enquanto as que não dispõem de medidas predominam entre aquelas menos estruturadas, seja internamente, seja em seu contexto territorial. 


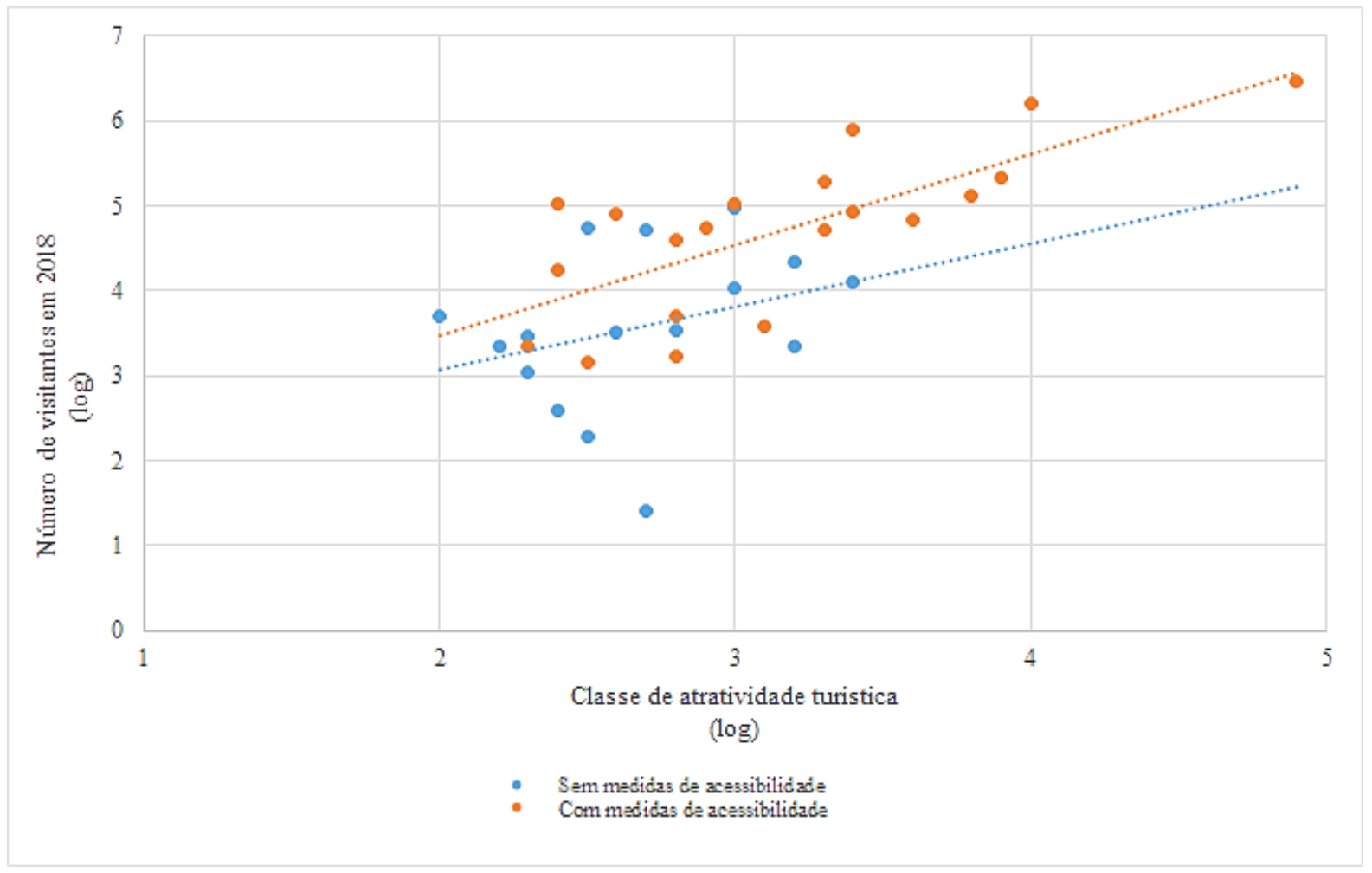

Figura 4 - Unidades de conservação com e sem medidas de acessibilidade em função da classe de atratividade turística e do número de visitantes, com medidas: $\mathrm{y}=1,06 \mathrm{x}+1.36, \mathrm{R}^{2}=0,54$; sem medidas: $\left.\mathrm{y}=0,74 \mathrm{x}+1,57, \mathrm{R}^{2}=0,10\right)$. As classes de atratividade turística são: 1 . primitiva; 2. semiprimitiva; 3. extensiva; 4. intensiva; 5. altamente intensiva (Souza et al., 2017).

Fonte: dados desta pesquisa, do ICMBio, para número de visitantes, e de Souza et al. (2017), para as classes de atratividade.

Existe aparentemente um reforço positivo entre as condições do entorno da UC na promoção do uso público, a sua estruturação interna $e$ a atração de visitantes, que também se relacionam com diversificação de oportunidades e por cobrança salutar por parte da sociedade por novas oportunidades, em que se inclui a acessibilidade.

\section{Atividades e infraestrutura de uso público}

A partir de uma lista abrangente de atividades e de estruturas de uso público, elaborada por Souza (2016), foi perguntado no presente estudo se para cada uma delas existe alguma medida implementada de eliminação de barreiras de acesso a pessoas com deficiência física, visual, auditiva ou intelectual. As Figuras 5 e 6 trazem estes resultados com o número de ocorrências para cada caso - se uma certa estrutura é adaptada para os quatro tipos de deficiência, ela será citada quatro vezes no gráfico.
Das 70 UCs respondentes, 64 informaram que desenvolvem atividades voltadas ao público (91\%), porém a maioria, neste conjunto, não é acessível (61\%). Em relação às atividades adequadas às pessoas com deficiência, a maior parte é dirigida às pessoas com deficiências físicas (39\%), seguidas às voltadas para pessoas com deficiências visuais e auditivas (ambos com $23 \%$ ) e intelectuais (22\%). Esta assimetria entre acessibilidade arquitetônica (dirigida à deficiência física) e a acessibilidade comunicacional (deficiência visual, auditiva, intelectual) fica bem caracterizada também nas descrições de muitas das soluções de acessibilidade trazidas pelos gestores, embora sejam mencionadas intervenções como piso tátil e trilhas sensoriais.

Embora os comentários feitos pelos gestores, referentes às estruturas de uso público, mostre que a maior parte das iniciativas se refere à acessibilidade para deficientes físicos, notadamente cadeirantes, na classificação da 
acessibilidade nas diversas atividades de recreação (Figura 5) e nas estruturas de uso público (Figura 6), atribui-se quase uma equitabilidade na acessibilidade para deficientes físicos, visuais, auditivos e intelectuais, claramente entendo-se a acessibilidade como a possibilidade de alcançar, $e$ não como uma medida de possibilidade de pleno desfrute da experiência.

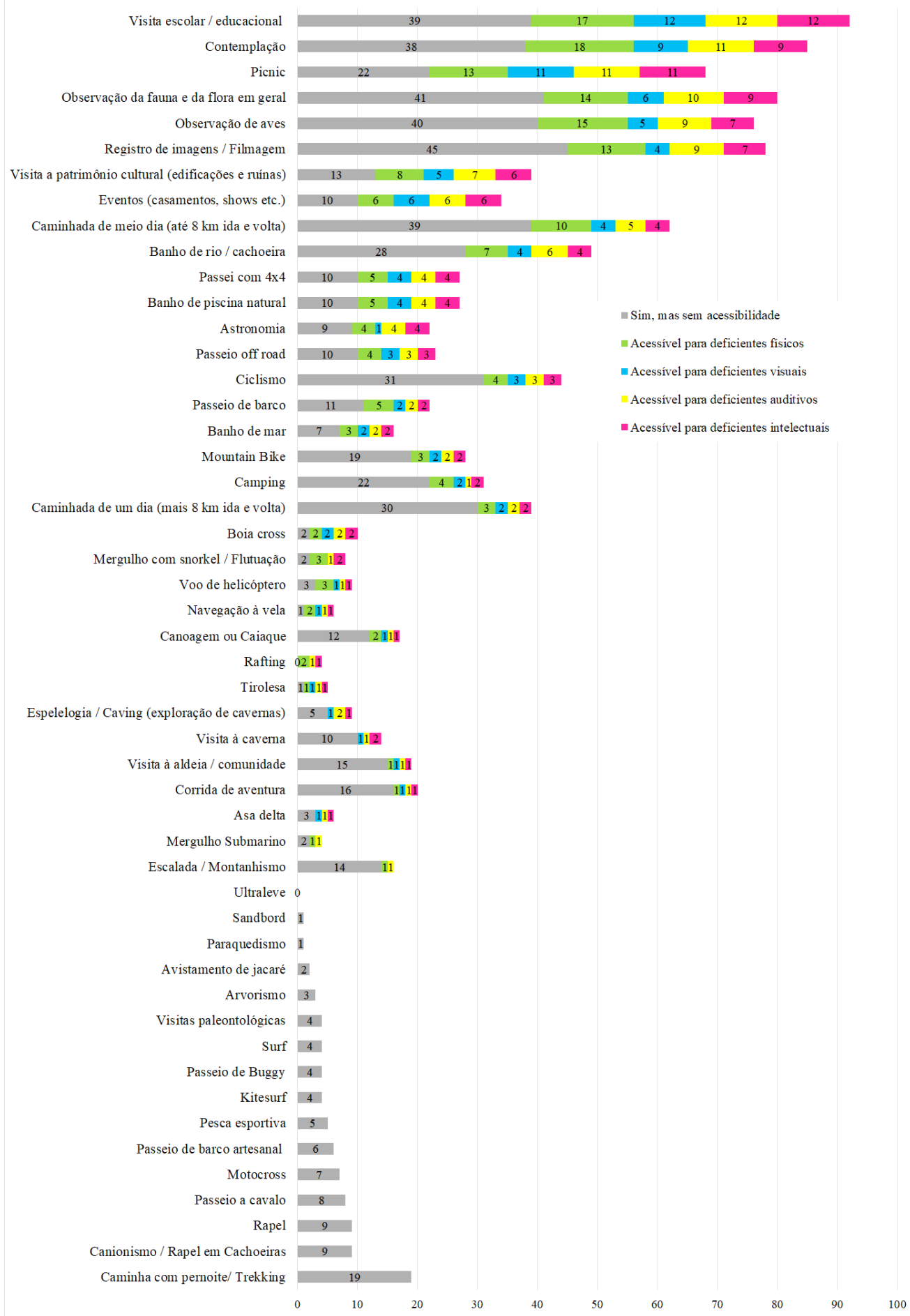

Figura 5 - Frequência de ocorrência de acessibilidade para diferentes tipos de deficiência nas várias modalidades de atividade, em 70 unidades de conservação nas categorias parque nacional e floresta nacional, conforme informações prestadas pela equipe gestora de cada UC. Em cinza consta o número de UCs que dispõem de uma certa atividade sem que haja acessibilidade, e em cores está a frequência de acessibilidade para cada categoria - deficientes físicos (verde), visuais (azul), auditivos (amarelo) e intelectuais (vermelho); deve-se observar que se uma mesma UC será computada múltiplas vezes em cada barra, conforme o número de categorias de acessibilidade que declarar para cada atividade. 


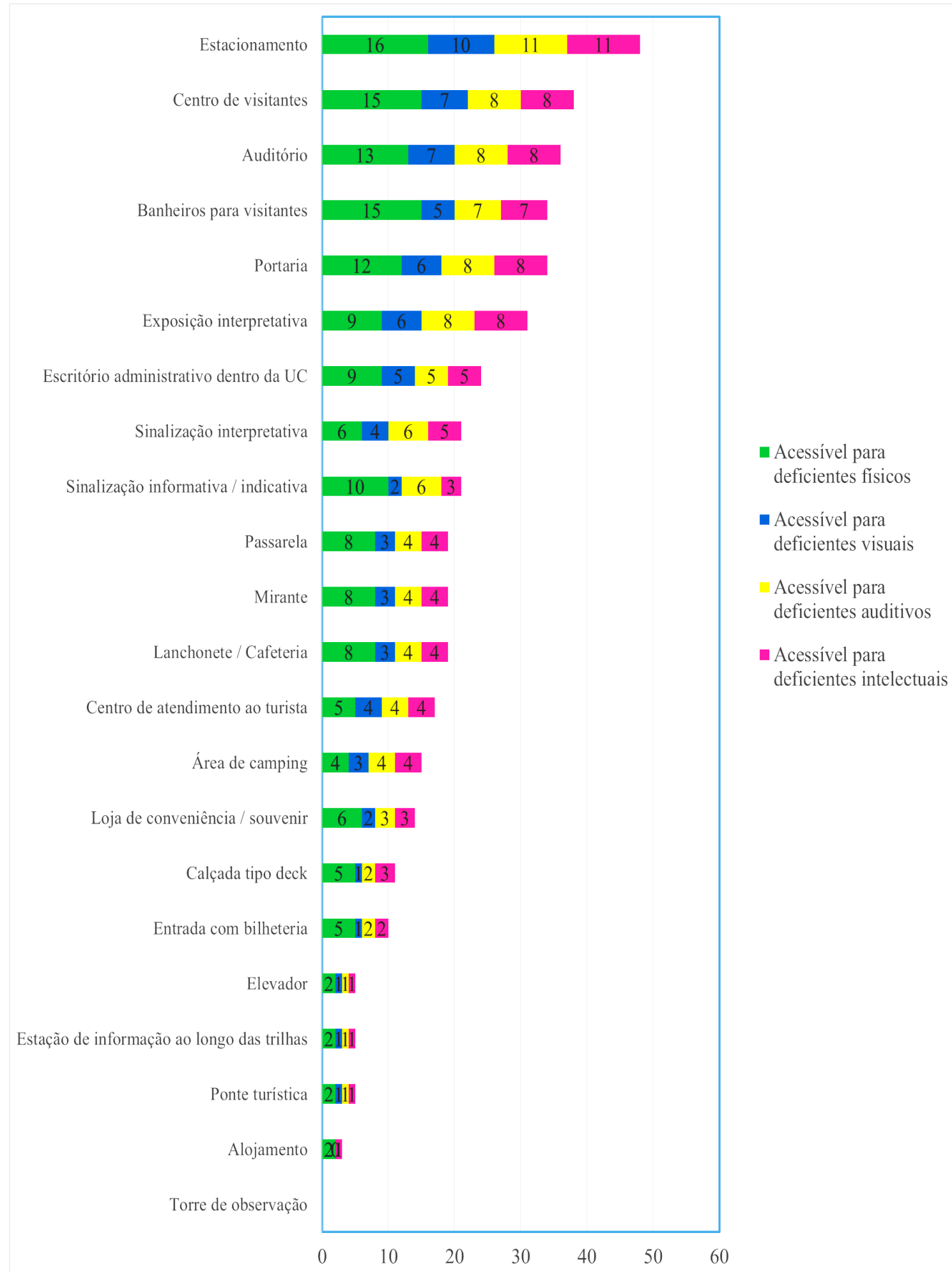

Figura 6 - Frequência de ocorrência de acessibilidade nas estruturas de uso público conforme tipos de deficiência, em 70 unidades de conservação nas categorias parque nacional e floresta nacional.

Há muitas respostas imprecisas a respeito da existência de acessibilidade nas atividades $e$ infraestruturas das unidades. Algumas pessoas dizem que há acessibilidade, mas na verdade promove-se atividade com pessoas com deficiência sem haver preparação devida. Por exemplo, algumas pessoas afirmam que há atividades acessíveis a deficientes auditivos basicamente 
porque as pessoas surdas podem caminhar por uma trilha, mas as unidades não estão estruturadas e suas equipes não estão treinadas para recebê-las adequadamente. Outras afirmam que determinada atividade ou estrutura não tem acessibilidade e, ao mesmo tempo, que é acessível para alguns tipos de deficiência (as respostas não eram mutuamente excludentes), indicando que, se não estão ainda preparados, mesmo assim recebem esse público, possivelmente em situações que não exigem maiores adaptações ou de forma improvisada. $\mathrm{O}$ fato de o representante da unidade afirmar que esta ou aquela atividade ou estrutura possui alguma medida de acessibilidade implementada, pode não significar que está de fato em conformidade com as normas vigentes, mas pode indicar que a equipe é mais propensa ou habituada a receber esse público. Como se trata de uma declaração da equipe da UCs sem uma orientação estruturada sobre termos e definições, é natural que haja um certo grau de subjetividade e imprecisão.

Os comentários abaixo ilustram algumas situações em que certas atividades, apesar de não estarem de acordo com os padrões de acessibilidade, foram marcadas como passíveis de serem usufruídas, eventualmente, por esse público.

"Há uma área aberta gramada, com quiosque, sem grandes obstáculos, o que possibilita algumas atividades neste espaço com este público"; "A UC possui caminhos de terra e parte com pequenos trechos de estradas asfaltadas no seu interior, o que proporciona atividades para deficiência física, visuais, auditivos e intelectuais."; "Atividades tais como visitas às áreas de uso público (exceto trilhas) e visitas escolares não oferecem barreiras no critério acessibilidade, salvo melhor juízo."; "Não há infraestrutura ou equipamento específico, mas com o apoio dos prestadores de serviço é possível praticar as atividades marcadas. Nota-se que observação de aves/ fauna/etc. sugere-se contemplação (pois deficientes visuais, por exemplo, podendo interagir ao ouvir os sons de alguns dos animais, os cheiros produzidos etc.)."; "Os principais atrativos da UC são acessados a partir da visita embarcada e no mar. Contando com o apoio das tripulações envolvidas as práticas tornam-se acessíveis, ainda que sem dispor de infraestrutura ou equipamentos específicos."

\section{Demanda por parte de visitantes}

A procura por serviços inclusivos para pessoas com deficiência, segundo $43 \%$ das respostas, é baixa. É entendida como razoável em $23 \%$ das respostas, nula em $21 \%$, alta em $10 \%$ e muito alta em apenas 3\%. Parece haver uma demanda maior por esses serviços no subconjunto de UCs que já dispõem de medidas que facilitam o acesso: razoável procura com $48 \%$, alta com $16 \%$ e muito alta com $4 \%$, consonante com as observações de que a promoção da acessibilidade é motivada por uma demanda local, seja do gestor, da comunidade ou de usuários, e é mais frequente em unidades de maior visitação de público, seja com ou sem deficiência (Figura 4).

Perguntou-se também sobre a variação da frequência de visitantes após introduzidas as iniciativas de eliminação de barreiras de acesso. Com relação aos visitantes com deficiência, não se percebeu variação em $8 \%$ dos casos, uma pequena variação em $62 \%$ dos casos e uma variação razoável em $23 \%$ dos casos, a partir de 13 respostas. Com relação às pessoas com mobilidade reduzida, a partir de 19 respostas, as respostas foram análogas em $11 \%$ dos casos não se percebeu variação; que foi pouca em $53 \%$ dos casos e razoável em $21 \%$.

Tais respostas sugerem que a demanda local por serviços de acessibilidade fortalece a implementação dessas iniciativas e que, por outro lado, tais iniciativas, ao serem implementadas, estão favorecendo em certa medida a visitação desse público, que passa a desfrutar de uma nova oferta de lazer, mas são ainda situações $e$ resultados incipientes.

$\mathrm{O}$ registro do número de visitantes com deficiência é feito em cinco UCs: na Floresta Nacional de Ipanema (SP) e nos Parques Nacionais da Chapada dos Veadeiros (GO), Descobrimento (BA), Fernando de Noronha (PE) e Araucárias (SC). Três delas informaram o total de visitantes com deficiência, que em 2017 foi de 5 (PARNA Chapada dos Veadeiros), 12 (PARNA Pau Brasil) e 77 pessoas (FLONA de Ipanema). Em somente uma das UCs colhem-se impressões acerca do nível de satisfação, expectativa e outras manifestações desses visitantes a respeito da experiência nos espaços e atividades acessíveis. 


\section{Capacitação de recursos humanos}

Não houve relato de iniciativa de capacitação para $\mathrm{o}$ atendimento a pessoas com deficiência por parte de nenhuma das equipes que enviaram respostas aos questionários, $e$ somente cinco unidades afirmaram dispor de quadros treinados para esse atendimento, com destaque para a participação de funcionários das concessionárias ligadas às unidades e a parceria com ONG especializada. Dado o crônico déficit de pessoal nas UCs brasileiras, é natural que prevaleça um atendimento mais especializado onde há equipes complementares.

\section{Divulgação}

As iniciativas que oferecem acesso às pessoas com deficiência ou mobilidade reduzida têm divulgação direcionada ao público de interesse em apenas seis unidades. Esse número corresponde a $24 \%$ das 25 UCs que afirmaram ter alguma medida de eliminação de barreiras de acesso implementada. Os veículos utilizados para essa comunicação são, de acordo com os comentários, as mídias sociais de forma genérica, a página institucional do ICMBio, panfletos, e uma menção específica "à Semana de Acessibilidade em setembro, com contato direto com instituições parceiras da região".

A maioria dos responsáveis pelas respostas (86\%) considera que as unidades de conservação estão pouco ou nada $(44 \%$ e $42 \%$, respectivamente) preparadas para receber pessoas com deficiência; $12 \%$ consideraram que as UCs pelas quais respondem têm condições razoáveis $e$ $2 \%$ que estão bem ou muito bem preparadas ( $1 \%$ cada). Por outro lado, perante a pergunta sobre o quanto consideram importante a acessibilidade nas UCs em uma escala de zero a dez, obteve-se uma média 8,74 para as 70 respostas.

\section{Percepções de visitantes com deficiência ou mobilidade reduzida}

Das 70 UCs participantes da etapa anterior, 15 responderam positivamente à solicitação de aplicação de questionário a visitantes, mas somente três efetivamente os aplicaram com sucesso: dois parques nacionais e uma floresta nacional, a um total de 19 visitantes com deficiência ou mobilidade reduzida. Estas unidades estão entre as que declararam não haver implementado medidas de eliminação de barreiras de acesso, mesmo possuindo uma demanda razoável deste público.

\section{Perfil dos participantes da pesquisa}

A maioria dos visitantes com deficiência ou mobilidade reduzida que participaram da pesquisa possuem entre 46 e 65 anos (37\%), seguidos por pessoas na faixa etária de 30 a 45 anos (26\%), acima de 65 anos (21\%) e menor que 15 anos (16\%). As pessoas com deficiência física representam a maior parcela dos respondentes, com $32 \%$, seguidas pelas pessoas com mobilidade reduzida (26\%) e deficiência intelectual (21\%). Nenhum visitante com deficiência visual ou auditiva participou da pesquisa.

Foi perguntado aos participantes sobre a frequência com que visitam UCs, o meio de transporte utilizado $e$ as principais barreiras que dificultam a visita (Tabela 2). A maior parte das pessoas respondeu que visitam unidades algumas vezes - 4 vezes/ano ou raramente - 1 a 3 vezes/ano (ambos 32\%). O carro particular é o principal meio utilizado ( $74 \%$ das respostas), seguido por excursão (16\%) e a pé ou por outro meio $(11 \%)$. Segundo os visitantes, os principais fatores que dificultam a sua maior frequência de vista são a falta de acessibilidade $(42 \%)$ e o transporte (37\%).

Os participantes informaram também a quantidade de pessoas (familiares, amigos $e$ cuidadores) que os acompanharam na visita: os 14 que responderam a essa questão foram em média acompanhados por 6,5 pessoas, ou 91 pessoas no total.

\section{Avaliação quanto à acessibilidade}

A esses visitantes foi perguntada sua opinião a respeito do nível de preparo da unidade visitada, considerando três dimensões do uso público: infraestrutura, atividades/serviços oferecidos e atendimento.

$\mathrm{O}$ atendimento ao público foi a dimensão melhor avaliada: para $68 \%$ a unidade está preparada em termos de atendimento; para $21 \%$, está parcialmente e para apenas $5 \%$ não está preparada. As atividades e serviços oferecidos foram avaliados de forma positiva apenas por 
$26 \%$ dos respondentes, parcialmente por $53 \%$ e negativamente por $16 \%$. A infraestrutura foi avaliada como positiva também por $26 \%$, parcialmente preparada por $42 \%$ e não preparada por $32 \%$.

Quanto ao resultado da visita, contudo, os participantes fizeram uma avaliação mais positiva, considerando em sua maioria (79\%) que a visita à unidade alcançou as expectativas. Somente um visitante assinalou que a visita não alcançou suas expectativas. Os respondentes deram uma nota de zero a dez com relação ao quesito acessibilidade para as três UCs visitadas, cujas médias foram 9, 6,3 e 0 .

Os comentários abaixo foram feitos pelos participantes como sugestão de melhoria para o aprimoramento da questão do acesso.

"Mais cascalho no caminho $e$ corrimão"; "Banheiro mais conservado"; "Cerca, tampar buracos no caminho, perigo para crianças"; "Poderia colocar mais acessibilidade para chegar até a cachoeira"; "Melhorar o acesso para idoso"; "Deveria ter corrimão nas trilhas de acesso à cachoeira. Mais fiscalização de pessoas."; "Corrimão de madeira."; "Construir uma acessibilidade para deficiente físico."; "Inserir rampas de acesso do estacionamento até a churrasqueira e inserir banheiro adaptado para cadeirante."

\section{Importância e benefício da visita}

$\mathrm{O}$ último grupo de perguntas se referiu à importância dada à visita pelos respondentes, bem como aos benefícios proporcionados por ela. As respostas indicaram que ao público com deficiência e mobilidade reduzida a visita proporcionou bemestar mental (74\%), bem-estar físico (68\%), maior consciência ambiental (53\%) e maior convívio com as pessoas (32\%). Nenhum visitante afirmou que a visita não teve importância.

Também foi perguntado se a visita proporcionou aos visitantes o aumento do conhecimento acerca da unidade visitada e da biodiversidade, e se aumentou seu sentimento de conexão com a natureza. Os visitantes afirmaram, em sua maioria, que seu conhecimento acerca da unidade visitada aumentou bastante (42\%) $e$, acerca da biodiversidade, que igualmente aumentou bastante (32\%). Eles afirmaram, ainda, que a visita aumentou bastante ou aumentou pouco seu sentimento de conexão com a natureza (37\% em ambos).

\section{Discussão}

\section{O acesso ao paraíso é para todos?}

Um importante número de pesquisas demonstra que o contato com a natureza selvagem pelavisitaçãoemáreasprotegidasproporcionabemestar físico, mental e espiritual às pessoas (Maller et al., 2009; Townsend et al., 2015). A visitação, ao mesmo tempo, aproxima as áreas naturais protegidas da sociedade e favorece a construção de uma cultura conservacionista em relação a essas áreas. São muitas as razões para aproximar as pessoas dos parques, com a diversificação de atividades e identificação daquelas com maior potencial de gerar experiências significativas com a natureza, inclusive para promoção de atitudes pró-ambientais e positivas em relação às áreas protegidas (Wright \& Matthews, 2015).

$\mathrm{O}$ potencial de visitação das pessoas com deficiência e mobilidade reduzida é um fator a ser considerado. As pessoas com deficiência representam uma parcela significativa da sociedade - no Brasil, são cerca de $23,9 \%$ das pessoas com algum grau de deficiência, 6,7\% que se declararam com deficiência mais severa, $e$ as pessoas com mais de 65 anos representam 7,38\% (IBGE, 2010, 2012). No mundo, segundo a Organização Mundial da Saúde (OMS, 2011), estima-se em um bilhão o número de pessoas com algum tipo de deficiência, ou $15 \%$ da população mundial. Esta parcela da população cada vez mais busca destinos turísticos e atrações providos com acessibilidade - cerca de $11 \%$ na Austrália e 12\% da população no Reino Unido (UNWTO, 2013). Até 2020, 25\% do mercado do turismo mundial incluirá pessoas com deficiência (Parks Victoria, 2015).

O direito de ir e vir está entre os direitos fundamentais da Declaração de Direitos Humanos $e$ da constituição brasileira, e a legislação associada estabelece que as pessoas devem ter oportunidades iguais em todas as áreas, incluindo o lazer e a recreação, o que resulta de longa e intensa história de lutas e conquistas de direitos para o exercício pleno da cidadania. Uma revisão dessas conquistas e legislação para o caso das áreas naturais pode ser encontrada em Souza \& 
Ribeiro (2021). No entanto, a previsão legal, por si só, não garante na prática o usufruto desse direito.

Os impedimentos de acesso, em suas várias expressões (vide Sassaki, 2003) são realidade em todas as áreas e setores, no público e no privado, e nas unidades de conservação não é diferente. Os parques e afins são lugares de descobertas, vivências e encontros sociais e, por serem em sua maioria áreas públicas, deveriam implementar a democratização de acesso e de experimentação a toda a sociedade, ampliando o rol de frequentadores. Atingir esse objetivo é um grande desafio, e começa por uma mudança na cultura dos agentes políticos, institucionais $e$ da comunidade envolvida. Passa também pelo entendimento de que, além de estar previsto em lei e da correção ética de fazê-lo, esta ação pode gerar benefícios extremamente positivos não só para as pessoas como para a própria conservação das áreas protegidas (Wright \& Matthews, 2015). De modo geral, a implementação do uso público, com diversificação de atividades, fortalece a economia local e regional e amplia o rol de pequenos negócios (Souza et al., 2018)

Obviamente, a promoção da acessibilidade se insere no complexo conjunto de desafios para promover e fortalecer o uso público em geral nas UCs, que por sua vez tem relação direta com o grau de implementação da gestão destas áreas e com a variedade de contextos locais $e$ regionais. Como argumenta e demonstra Viveiros de Castro (2018) a partir de um estudo de caso, a intensidade do uso público tem relação direta com o grau de implementação de diversos outros indicadores de gestão, provavelmente como uma consequência, mas também como um provável elemento propulsor do fortalecimento da gestão. Por exemplo, a presença de visitantes fortalece a busca dos locais por pesquisadores, torna mais robusta a atuação dos conselhos gestores, o que promove parcerias, amplia a visibilidade a questões e públicos até então não percebidos, $e$ assim por diante.

Ainda são poucas as pesquisas desenvolvidas sobre o tema acessibilidade em UCs no Brasil. Em geral, convergem para a constatação da necessidade da ampliação e diversificação das ofertas, assim como para a divulgação das iniciativas já existentes, capacitação do pessoal para atendimento especializado, mudança de cultura e conscientização da sociedade para a importância de favorecer o exercício da cidadania das pessoas com deficiência e mobilidade reduzida (Carvalho, 2012; Oliveira et al., 2013; Julião \& Ikimoto, 2007; Leite, 2004; Luiz \& Teixeira, 2016; Moriwaki \& Neiman, 2011; Nascimento \& Paz, 2015; Pinto 2017). De acordo com Julião \& Ikimoto (2007), a garantia do acesso às UCs vai além da questão da disponibilidade financeira ou de recursos humanos; ela passa pela superação de barreiras muitas vezes imperceptíveis à sociedade, com a falta de inserção dessa perspectiva nas políticas e projetos públicos, de modo a se conceber ambientes e produtos a partir de uma visão sistêmica da acessibilidade.

Em um país reconhecido por sua megadiversidade, pela diversidade de paisagens $e$ contextos sociais e culturais riquíssimos, com numerosas formas possíveis de recreação $e$ de práticas de esporte em contato com o meio natural, é primordial viabilizar o acesso a parcela tão significativa da população, e que é especialmente grata e positivamente impactada pelas poucas oportunidades que se apresentam. Esse patrimônio não pode ser para alguns, o acesso a ele deveria estar ao alcance de toda a população, considerando também as barreiras socioeconômicas, que intensificam as limitações vividas pelas pessoas com deficiência.

Como mostramos neste trabalho, há um conjunto interessante de iniciativas pontuais de promoção da acessibilidade em áreas naturais protegidas. As trilhas suspensas, as trilhas sensoriais, adaptações em centro de visitantes, a cadeira Julietti do projeto Montanha para Todos, acesso ao banho de mar, são alguns exemplos de iniciativas que democratizaram o acesso a algumas unidades. Não se observou uma relação consistente entre a existência de iniciativas de promoção da acessibilidade com sua previsão nos documentos de manejo, e a maioria das iniciativas existentes é voltada para pessoas com deficiência física. Os representantes das UCs declararam que há infraestruturas e atividades de uso público acessiveis para outros grupos de deficiência, porém percebe-se que não estão devidamente preparados e em conformidade com as normas de acessibilidade vigentes. Essa ênfase na acessibilidade nas estruturas ocorre em diversos outros contextos.

O baixo número de UCs com uso público implementado que têm a questão da acessibilidade constante em plano de manejo ou plano de uso público evidencia a importância de 
se exigir esta dimensão nos planejamentos futuros e suas revisões, especialmente no que se refere às estruturas e serviços oferecidos, a partir também de um debate para ampliação do entendimento sobre o que se entende como acessibilidade, para além das normas técnicas. Estas são importantes, mas não suficientes.

Os resultados evidenciam a falta de uma orientação geral sobre o tema; as ações surgem de um atendimento genérico à legislação, no caso das novas obras, mas sem uma diretriz geral de acessibilidade e inclusão, de modo que as iniciativas surgem por demandas ou expectativas locais. A legislação sobre o tema é extensa e prevê obrigatoriedade de acesso a todos, em igualdade de condições, inclusive no que se refere ao lazer $e$ recreação em ambiente naturais, embora não exista regulamentação legal específica sobre acessibilidade em UCs e normatização sobre espaços e serviços que lhes são próprios (trilhas, cachoeiras, mirantes, interpretação ambiental, visita guiada etc.).

Observa-se, então, que muitos espaços são referidos como adaptados ou acessíveis, mas na realidade encontram-se "parcialmente" acessíveis (Carvalho, 2012), contemplando esse ou aquele tipo de restrição de mobilidade ou deficiência ou adaptando determinados espaços de um ambiente em detrimentos de outros tão ou mais importantes para se promover uma visitação de qualidade. Além disso, muitos dos projetos são executados sem a participação dos seus maiores interessados, ou seja, os planejadores não consultam os desejos e necessidade dos próprios usuários em potencial, o que geralmente resulta em projetos não-funcionais. Sem a participação dos reais interessados, que sabem melhor do que ninguém das suas reais dificuldades e necessidades, dificilmente um projeto de acessibilidade fica satisfatório.

Com relação ao acesso ao conhecimento disponível em cada UC, é importante destacar o papel do centro de visitantes como disseminador das informações e a necessidade de que estejam disponíveis em formato acessível para todos, em especial sobre os ambientes que efetivamente não podem ser acessados por determinado grupo $\mathrm{de}$ pessoas. Nesse contexto, vale ressaltar que a acessibilidade pode ser entendida em um sentido lato sensu ao se pensar não só ao acesso físico àquele bem, mas também à informação que ele traz (Ribeiro, 2014).
Além da falta de conhecimento técnico sobre a questão da acessibilidade, a falta de recursos financeiros $e$ operacionais foram as principais causas apresentadas para a não ocorrência de acessibilidade nas UCs. Sobre a falta de recursos, importa considerar que a relação entre a promoção da acessibilidade e grandes investimentos nem sempre é verdadeira, porque as principais mudanças necessárias não são as grandes obras: elas são programáticas, metodológicas e, muitas vezes, invisíveis, mas potentes. A transformação primordial é a de ordem cultural, da percepção das pessoas em relação à acessibilidade de uma forma global, considerando, não somente o acesso físico propriamente dito, mas também o acesso à informação e ao conhecimento (Julião \& Ikemoto, 2007).

Fica claro que as barreiras de acesso são mais uma barreira de ordem institucional do que comportamental, que está no nível pessoal, da pessoa imaginar que pode visitar esses lugares $e$ assim alimentar o seu querer. Se só onde já há demanda se fizer a ação, as barreiras persistirão. É necessário que se crie uma força em outro sentido - estruturar de forma sistêmica a visitação com vistas à acessibilidade entendida de forma ampla, passando pela construção de um outro imaginário, que amplia o próprio desejo $e$ as expectativas $e$ cobranças de que as possibilidades de escolha sejam ampliadas. É importante que as percepções dos visitantes sejam acompanhadas, mas também dos que não chegam às UCs, para que sejam compreendidas as razões e buscadas soluções.

As concessões de serviços de uso público nas UCs mostram-se como uma excelente oportunidade para a promoção da eliminação de barreiras de acesso especialmente com o advento da Lei $\mathrm{n}^{\circ} 13.668 / 18$ e da Instrução Normativa ICMBio ${ }^{\circ} 2 / 17$ que as regulamentam. É mandatório e oportuno incluir nos programas de concessão o tema da acessibilidade e dos seus benefícios para a saúde e para a conservação dos parques. A concessão implica em investimento, como contrapartida da concessionária, em melhorias na infraestrutura e na ampliação de oferta de serviços. Para isso, é muito importante que ao se investir em melhoria da infraestrutura, a eliminação de barreiras esteja prevista. Nesse sentido, importa também que haja a previsão desta acessibilidade nos planos de manejo, dentro dos planos de uso público, das UCs onde a visitação faça parte de seus objetivos. 
É necessário que se pense em estratégias para que essa mobilização institucional possa acontecer. Casos de sucesso de outros países, como os dos EUA e do Chile, apresentados em Souza \& Ribeiro (2021), podem e devem servir de inspiração para se estabelecer um plano nacional de acessibilidade das UCs que envolva necessariamente a sensibilização de todos os agentes envolvidos, a capacitação de servidores, a produção de diretrizes e documentos orientadores $e$ normativos $e$ a priorização de ações visando à otimização dos recursos e à eficiência das medidas.

\section{Conclusões e Recomendações}

Para que mudanças significativas sejam alcançadas, é fundamental que haja uma mobilização institucional dos órgãos gestores, assim como o envolvimento dos agentes políticos e das organizações sociais para que seja criada uma agenda positiva em torno do tema. Propomos, a partir deste estudo, alguns possíveis caminhos para que esse desafio possa ser enfrentado de forma efetiva e venha a gerar bons frutos para toda a sociedade.

1) Desenvolver ações de sensibilização direcionadas aos servidores dos órgãos gestores, agentes políticos e comunidade que visem a uma mudança cultural em relação à questão da acessibilidade nas UCs, envolvendo campanhas de comunicação, capacitação, realização de eventos (como semana da acessibilidade, seminários $e$ palestras com especialistas da área), entre outros.

2) Estabelecer um grupo de trabalho ou comissão de acessibilidade reunindo servidores do ICMBio (e também no âmbito dos órgãos gestores estaduais e municipais), especialistas da área e representantes de organizações representativas para discutir, propor e acompanhar medidas de aprimoramento da acessibilidade nas UCs federais.

3) Desenvolver plano de ação para promoção da acessibilidade e mudança de cultura no âmbito das UCs federais ou do SNUC, com metas de curto, médio e longo prazos, tendo como inspiração experiências bemsucedidas na área ou desafios análogos de internalização de novos desafios na gestão de áreas protegidas.

4) Conceber diretrizes institucionais de acessibilidade para as UCs federais ou para o SNUC, com vistas a torná-lo mais inclusivo mediante a eliminação dos diferentes tipos de barreiras de acessibilidade.

5) Incluir o tema da acessibilidade nos documentos normativos e programáticos do órgão gestor.

6) Eleger as UCs mais favoráveis para priorização de investimentos mediante critérios como: visitação, proximidade de grandes centros e capitais, tipos de atividade $e$ estruturas de uso público, potencial turístico, entre outros.

7) Estabelecer parcerias com organizações estrangeiras com expertise reconhecida no assunto (HPHP, NPS/Park Rx) para troca de experiências, treinamentos e seminários.

8) Incluir a temática da acessibilidade em seminários sobre o benefício do contato com a natureza em áreas protegidas para a saúde humana.

9) Melhorar a divulgação das iniciativas já existentes e futuras nos canais oficiais do ICMBio e das respectivas unidades.

10) Oferecer treinamentos voltados para $o$ atendimento a pessoas com deficiência, Libras e outros para servidores e profissionais da área que trabalham com UCs.

11) Criar uma rede virtual (hotsite) sobre acessibilidade em UCs, contendo a lista de unidades com medidas consistentes de acessibilidade, informações úteis sobre viagem e acessibilidade e mapa interativo online com as unidades que apresentam iniciativas de acessibilidade implementadas.

Ainda que pareça um grande desafio transformar as UCs em ambientes amplamente inclusivos, haja vista o cenário de falta de recursos e da aparente complexidade e da dificuldade de viabilizar tal empreendimento em áreas selvagens, iniciativas criativas já existentes no Brasil e experiências bem-sucedidas de fora do país mostram que é possível e que o horizonte pode ser bastante promissor. 


\section{Agradecimentos}

RGR Souza agradece a Márcia Lima pela companhia e inspiração. O trabalho é parte da dissertação de mestrado do primeiro autor, $e$ ambos agradecem a todos que gentilmente participaram da pesquisa (frequentadores das UCs e gestores/servidores), que contou apenas com recursos financeiros pessoais, e a João Madeira e aos revisores anônimos pela leitura cuidadosa.

\section{Referências}

ABNT - Associação Brasileira de Normas Técnicas. 2015. ABNT NBR 9050:2015. Acessibilidade a edificações, mobiliário, espaços e equipamentos urbanos. Rio de Janeiro. Disponível em: <https:// www.ufpb.br/cia/contents/manuais/abnt-nbr9050edicao-2015.pdf> Acesso em: 20/05/2019.

Aguiar PCB, Moreau AMSS \& Fontes EO. Áreas naturais protegidas: um breve histórico do surgimento dos parques nacionais e das reservas extrativistas. Revista Geográfica de América Central, 50(1): 195-213, 2013.

Carvalho SMS. Acessibilidade do Turismo no Parque Nacional Serra da Capivara/PI. Revista Turismo em Análise, 23(2): 437-463, 2012.

CORDE - Coordenadoria Nacional para Integração da Pessoa Portadora de Deficiência. 2008. A Convenção sobre os Direitos das Pessoas com Deficiência comentada. Secretaria Especial dos Direitos Humanos. Brasília. 164p. Disponível em: <https://www. governodigital.gov.br/documentos-e-arquivos/A\%20 Convencao\%20sobre\%20os\%20Direitos\%20das\%20 Pessoas\%20com\%20Deficiencia\%20Comentada.pdf> Acesso em: 20/05/2019.

Diegues ACSA. 2000. O mito moderno da natureza intocada. Ed. Hucitec, Universidade de São Paulo. 3a edição. 169 p.

ETrilhas. Caminho D. Pedro Augusto. Disponível em: $<$ https://www.etrilhas.com.br/trilhas/caminho-d-pedroaugusto> Acesso em: 25 de julho de 2019. 2019.

Franco JLDA, Schittini GDM \& Braz VDS. História da Conservação da Natureza e das Áreas Protegidas: Panorama Geral. Historiæ, Rio Grande, 6(2): 233-270. 2015.

Fuller RA, Irvine KN, Devine-Wright P, Warren PH \& Gaston KJ. Psychological benefits of greenspace increase with biodiversity. Biology letters, 3(4): 390-394, 2007.

Gil AC. 2008. Métodos e técnicas de pesquisa social. Editora Atlas, São Paulo. 200p.
IBGE - Instituto Brasileiro de Geografia e Estatística. 2010. Distribuição da população por grandes grupos de idade. Disponível em: <https://brasilemsintese. ibge.gov.br/populacao/distribuicao-da-populacaopor-grandes-grupos-de-idade.html $>$ Acesso em: 22/05/2019.

IBGE - Instituto Brasileiro de Geografia e Estatística. 2018. Releitura dos dados de pessoas com deficiência no Censo Demográfico 2010 à luz das recomendações do Grupo de Washington. Nota Técnica 01/2018.

IBGE - Instituto Brasileiro de Geografia e Estatística. 2019. Projeção da população do Brasil e das Unidades da Federação. Disponível em: < https://www.ibge.gov. br/apps/populacao/projecao > Acesso em: 22/05/2019.

ICMBio - Instituto Chico Mendes de Conservação da Biodiversidade. 2017. Dados de Visitação 2007 2016. Coordenação Geral de Uso Público e Negócios. Disponível em: <http://www.icmbio.gov.br/portal/ images/stories/comunicacao/noticias/2017/dados_de_ visitacao_2012_2016.pdf> Acesso em: 24/07/2019.

ICMBio - Instituto Chico Mendes de Conservação da Biodiversidade. Parques do Brasil: iVisitar es proteger! Estrategias de implementación de la visitación en unidades de conservación federales: prioridades de ejecución 2018-2020. Coordinación General de Uso Público y Negocios. Brasília. Disponível em: < http:// www.icmbio.gov.br/portal/images/stories/comunicacao/ publicacoes/publicacoes-diversas/parques_do_brasil_ estrategia_implementacao_visitacao_2018_2020 ICMBio_espanhol.pdf > Acesso em: 18/05/2019.2019a.

ICMBio - Instituto Chico Mendes de Conservação da Biodiversidade. 2019b. Painel Dinâmico de Informações: Uso Público e Turismo. Disponível em: <http://qvicmbio.gov.br> Acesso em: 20 de fevereiro de 2019.

Julião DP \& Ikemoto SM. 2007. O direito ao lazer do deficiente visual em áreas naturais públicas e unidades de conservação. Anais do II Seminário de Áreas Protegidas e Inclusão Social. UFRJ, Rio de Janeiro. Disponível em: $<$ https://www.researchgate.net/profile/Silvia_Ikemoto/ publication/239549792_O_DIREITO_AO_LAZER DO_DEFICIENTE_VISUĀL_EM_AREAS_NATTURAIS PUB̈LICAS_E_UNIDADES_DE_CONSERVACAO/ links/57dd $\overline{9}$ af308aeea195938c9a9/O-DIREITOAO-LAZER-DO-DEFICIENTE-VISUAL-EMAREAS-NATURAIS-PUBLICAS-E-UNIDADES-DECONSERVACAO.pdf> Acesso em: 20/05/2019.

Leite CAG. 2019. Ecoturismo, terceira idade e tecnologia: estudos de acessibilidade em unidades de conservação. Dissertação de Mestrado. Instituto de Pesquisas Tecnológicas do Estado de São Paulo. 97p.

Li Q. Introduction to the Japanese Society of Forest Medicine. Disponível em: < http://forest-medicine.com/ epage01.html> Acesso em: 24/01/2019. 2008. 
Louv R. 2007. Leave No Child Inside. https:// orionmagazine org/article/leave-no-child-inside/. Acesso em: 22/02/2021

Luiz FI \& Teixeira JC. A acessibilidade de idosos $e$ as unidades de conservação: reflexões rumo à democratização dos espaços públicos de lazer. TurismoVisão e Ação, 18(1): 164-192, 2016.

Maller $\mathrm{C}$ et al. Healthy parks, healthy people: The health benefits of contact with nature in a park context. The George Wright Forum, 26(2): 51-83, 2009.

Moriwaki EM \& Neiman Z. Acessibilidade para pessoas com deficiência visual em Unidades de Conservação: estudo de caso do Parque Estadual do Jaraguá (SP). Anais do VIII Congresso Nacional de Ecoturismo e do IV Encontro Interdisciplinar de Ecoturismo em Unidades de Conservação. Revista Brasileira de Ecoturismo, São Paulo, 4(4): 523, 2011.

Nascimento JL \& Paz RJ. Avaliação da Floresta Nacional de Brasília para o atendimento de pessoas com deficiência e/ou mobilidade reduzida. Revista Brasileira de Gestão Ambiental e Sustentabilidade, 2(2): 3-23, 2015.

NPS - National Park Service. 2014a. All In: Accessibility in the National Park Service 2015-2020. Washington DC. 14p. Disponível em: <https://www.nps.gov/aboutus/ upload/All_In_Accessibility_in_the_NPS_2015-2020_ FINAL.pdf $>$ Acesso em: $20 / 05 / 201 \overline{9}$.

NPS - National Park Service. 2014b. Access National Parks: A Guide for Healthy Parks Healthy People. Community Engagement eGuide. Edition 1. 41p. Disponível em: <http://www.hphpcentral.com/casestudy/healthy-parks-healthy-people-communityengagement-eguide > Acesso em: 15/01/2019. 2014b.

NPS - National Park Service. Healthy Parks Healthy People Disponível em: <https://www.nps.gov/public health/hp/hphp.htm > Acesso em: 25/01/2019.

Oliveira DN, Souza JN, Cortinez E, Miranda BD \& Gomes OVO. 2013. Acessibilidade a Ambientes Naturais para Pessoas com Deficiência. IV Congresso Brasileiro de Gestão Ambiental, Salvador. Disponível em: <https:/www.ibeas.org.br/congresso/Trabalhos2013/ VII-066.pdf > Acesso em: 20/05/2019.

OMS - Organização Mundial da Saúde. 2011. Relatório Mundial sobre a Deficiência. Governo do Estado de São Paulo: Secretaria dos Direitos da Pessoa com Deficiência. 334p.

Park BJ, Tsunetsugu Y, Kasetani T, Kagawa T \& Miyazaki Y. The physiological effects of Shinrin-yoku (taking in the forest atmosphere or forest bathing): evidence from field experiments in 24 forests across Japan. Environmental health and preventive medicine, 15(1). 18, https://doi.org/10.1007/s12199-009-0086-9, 2010.
Park Rx. 2018. What are Park Prescriptions? Institute at the Golden Gate, a program of the Golden Gate National Parks Conservancy in partnership with the National Park Service. Disponível em: < http://parkrx. org/about> Acesso em: 18/01/2019.

Parks Victoria. 2015. A guide to the healthy Parks Healthy People approach and current practices: proceedings from the improving health and well-being: Healthy Parks Healthy People Stream. Em: IUCN World Parks Congress 2014, Sydney. Disponível em: <https:/www. iucn.org/sites/dev/files/content/documents/improvinghealth-and-well-being-stream-report_0.pdf $>$ Acesso em: 17/05/2019.

Parks Victoria. Healthy Parks Healthy People. Disponível em: <https://parkweb.vic.gov.au/about-us/healthyparks-healthy-people > Acesso em: 02/08/ 2019.

PARNASO - Parque Nacional da Serra dos Órgãos. Atrativos. Trilha Suspensa. Disponível em: <http:// parnaso.tur.br/atrativo/trilha-suspensa $>$ Acesso em : 02/08/ 2019.

List PC (ed.). 2000. Environmental forestry and ethics. Temple University Press. 364p.

Pinto SJR. 2017. Interpretação, avaliação e educação ambiental em trilha adaptada para pessoas com deficiência: o caso da Reserva Biológica União, RJ. Dissertação (Mestrado Profissional Biodiversidade em Unidades de Conservação). Instituto de Pesquisas do Jardim Botânico do Estado do Rio de Janeiro.

Razani $\mathrm{N}$ et al. Effect of park prescriptions with and without group visits to parks on stress reduction in low-income parents: SHINE randomized trial. PloS one 13(2): e0192921. https://doi.org/10.1371/journal. pone.0192921, 2018.

Ribeiro SB (Org.). 2014. Mobilidade e acessibilidade urbana em centros históricos. IPHAN. 120p. (Cadernos Técnicos; 9). Brasília. Disponível em: <http://portal.iphan.gov.br/uploads/publicacao/ CadTec9_CadernoAcessibilidade_m.pdf $>$ Acesso em: 03/04/20̄̄9.

Sassaki RK. 2003. Inclusão no lazer e turismo: em busca da qualidade de vida. Ed. Áurea, São Paulo.

Souza TVSB. 2016. Recreation classification, tourism demand and economic impact analyses of the federal protected areas of Brazil. Doctoral dissertation, University of Florida, Gainesville. 201p.

Souza TVSB, Thapa B, Rodrigues CGO \& Imori D. 2018. Economic impacts of tourism in protected areas of Brazil. Journal of Sustainable Tourism. DOI: 10.1080/09669582.2017.1408633.

Souza TVSB, Thapa B \& Castro EV. 2017. Índice de Atratividade Turística das Unidades de Conservação Brasileira. PAPP, Brasília. Disponível em: < http://www. 
papp.org.br/wp-content/uploads/2017/11/PesquisaIndice-de-atratividade-turistica_diagramado.pdf $>$ Acesso em: 03/08/2019.

Souza RGR \& Ribeiro KT. O Paraíso é Para Todos? Normas e Inspirações para Ampliar a Acessibilidade em Unidades de Conservação Brasileira. Biodiversidade Brasileira, submetido.

Souza RGR. 2019. O paraíso é para todos? Acessibilidade em Unidades de Conservação para pessoas com deficiência. Dissertação. (Mestrado Profissional Biodiversidade em Unidades de Conservação). Escola Nacional de Botânica Tropical, Jardim Botânico do Rio de Janeiro. 108p.

Tilden F. 1977. Interpreting our heritage. 3rd Ed. The University of North Carolina Press, Chapel Hill. 115p.

Townsend M, Henderson-Wilson C, Warner E \& Weiss L. 2015. Healthy Parks Healthy People: the state of the evidence. Prepared for Parks Victoria by School of Health and Social Development, Deakin University. Disponível em: <https://parkweb.vic.gov.au/_data/ assets/pdf file/0003/672582/HPHP state-of-theevidence_2015.pdf $>$ Acesso em: 20/05/2019.

Ulrich RS. View through a window may influence recovery from surgery. Science, 224(4647): 420-421, 1984.
UNWTO - World Tourism Organization. 2013. Recommendations on Accessible Tourism. Madrid: CEDRO, Centro Español de Derechos Reprográficos. 17p. Disponível em: <http://ethics.unwto.org/ publication/unwto-recommendations-accessibletourism-all> Acesso em: 20/05/2019.

Viveiros de Castro EB. (2018). Changing a Brazilian Protected Areas Paradigm: Why Public Use is Not Just Optional. Journal of Park and Recreation Administration, 36: 129-140. https://doi.org/10.18666/ JPRA-2018-V36-I3-8409

WHO - World Health Organization. 2015. Connecting global priorities: biodiversity and human health. World Health Organization and Secretariat of the Convention on Biological Diversity. Disponível em: < https://www. cbd.int/health/SOK-biodiversity-en.pdf $>$ Acesso em: 20/05/2019.

Wright PA \& Matthews C. Building a Culture of Conservation: Research Findings and Research Priorities on Connecting People to Nature in Parks. Parks, Vol 21.2. DOI: 10.2305/IUCN.CH.2014.PARKS21-2PAW.en, 2015.

Zarr R, Cottrell L \& Merrill C. Park prescription (DC Park Rx): A new strategy to combat chronic disease in children. Journal of Physical Activity and Health, 14(1): 1-2, 2017.

Biodiversidade Brasileira - BioBrasil.

Fluxo Contínuo

n. 3, 2021

http://www.icmbio.gov.br/revistaeletronica/index.php/BioBR

Biodiversidade Brasileira é uma publicação eletrônica científica do Instituto Chico Mendes de

Conservação da Biodiversidade (ICMBio) que tem como objetivo fomentar a discussão e a disseminação de experiências em conservação e manejo, com foco em unidades de conservação e espécies ameaçadas.

ISSN: 2236-2886 